\title{
Regional Industrial Water Demand Prediction Based on Improved Series Gray Neural Network
}

\author{
Zhen-Yun $\mathrm{Hu}$ \\ HOHAI UNIVERSITY; State Key Laboratory of Water Resorces and Hydrology and Hydraulic Engineering, Management \\ Science Institute, Nanjing, CHINA \\ e-mail: z_y_hu@sina.com
}

\author{
Zhi-Ming Chen \\ HOHAI UNIVERSITY, Business School, Nanjing, \\ China \\ e-mail: czm43@163.com
}

\author{
Wei Zhang \\ HOHAI UNIVERSITY, Business School
}

\begin{abstract}
The advantages of nonlinear adaptive gray theory weaken the ability of information processing data sequencespecific volatility and neural networks to construct an improved series gray neural network model system to Nanjing industrial water demand for the study, from 2000 to 2009 data as training samples of water, with water consumption data from 2009 to 2011 to test the model, the results show that the improved prediction series gray neural network model has higher precision and is a practical, strong prediction method finally predicted Nanjing $2015 \sim 2016$ industrial water demand.
\end{abstract}

Keywords-Industrial water demand forecasting; series gray neural network; Nanjing

\section{INTRODUCTION}

Since the reform and opening up, constantly improve the level of industrialization, a sharp rise in urban water consumption. By the end of 2013, China's urban population 731 million people, urbanization level up to $53.73 \%$, the total number of 661 cities, of which less than 400 urban water supply, 110 serious water shortages, accounting for $1 / 6$ of the total number of cities[1], water shortage has become a serious constraint of urban economic, social, demographic, environmentally sustainable and healthy development bottleneck.

Industry is the pillar industry of urban development, the city with the further adjustment of industrial structure, industrial water demand continues to increase the proportion of urban water demand. By the end of 2013, the country's industrial water consumption of about 140.64 billion $\mathrm{m}^{3}[2]$. Therefore, the scientific forecasting future urban industrial water demand of urban water supply and water resources has become an extremely important part of planning is the basis for solving the problem of water shortage in cities, but also an important research topic in the city to meet the long-term development.

Many developed countries from the 1960s gradually realized the importance of water demand for national economic development, China will continue to carry out from the early days of water demand forecasting research, but research methods, models are too simple and rough, the real water demand work began forecasting system, in-depth comprehensive research began in the 1980s[3]. At present, the common method of industrial water demand forecasts have quota laws, multivariate regression, trend forecasting method, the growth rate method, recycling rate method, system dynamics method, the macroeconomic model, gray prediction theory, time series, support vector machine, principal component analysis and neural network. Because of the importance of sustainable development of modern industrial society, the public industrial water demand prediction accuracy of proposed new requirements, the traditional industrial water demand forecast model is affected by many factors, material abundance, with its prediction accuracy is far meet the requirements of modern industrial society.

Therefore, this paper by way of a combination of patterns to build an improved series gray neural network model of urban industrial water demand forecasting, gray system and the advantages of BP network model to fully exploit, weakening the randomness of the system, to enhance learning and pan model capabilities, improve forecast accuracy.

\section{WATER DEMAND FACTORS}

Industrial water demand forecasting is a complex task, and its impact factor is a large, complex systems, nonlinear between various factors, complexity, variability and uncertainty when more difficult and increases the accuracy of the prediction of work [4].

The impact of industrial water demand factors are divided into direct and induced factors influencing factors, the former refers to those changes by itself can directly affect the industrial water demand factors, including urban scale and economies of scale both; the latter refers to by itself changes induced by changes in factors directly affect the ultimate impact of industrial water demand factors, including human and natural factors both factors [5]. Industrial water systems complex internal structure, influence the choice from the scientific, completeness factor, operability, dominant, independence, etc. particularity and dynamic principle, as effective factors include, exclude invalid factor. Industrial water demand specific impact factor in Table I 
TABLE 1 Water Demand Factors

\begin{tabular}{|c|c|c|c|}
\hline Types of water & $\begin{array}{l}\text { The first level factor } \\
\text { types }\end{array}$ & $\begin{array}{l}\text { The second level } \\
\text { factor types }\end{array}$ & factors \\
\hline \multirow{4}{*}{$\begin{array}{l}\text { Industrial water } \\
\text { demand factors }\end{array}$} & & City scale & $\begin{array}{l}\text { The population of the city, Industrial Park area, Amount of industrial enterprises, } \\
\text { Natural population growth rate }\end{array}$ \\
\hline & Direct factors & Economic scale & $\begin{array}{l}\text { Industrial added value, Economic growth rate, Quantity of water per unit of } \\
\text { product, The ratio of light and heavy industry, Electricity industry output, Water } \\
\text { demand in the power sector, Emissions from industrial wastewater, Industrial } \\
\text { water recycling rate, recycling rate water for the power industry, Industrial water } \\
\text { prices, Ten thousand yuan of industrial added value quantity of water, Per capita } \\
\text { GDP, Industrial fixed assets, Total water conservation, Index of industrial } \\
\text { progress, Industrial growth rate, Industrial wastewater reuse rate, Industrial } \\
\text { sewage treatment rate, Industrial output proportion of national economic output, } \\
\text { The rate of industrial wastewater discharge standards }\end{array}$ \\
\hline & \multirow{2}{*}{ Inducing factors } & Natural factors & $\begin{array}{l}\text { Total water resources, The annual rainfall, The annual evaporation, The average } \\
\text { annual temperature, Groundwater overdraft rate, A number of other local water, } \\
\text { Urban land area }\end{array}$ \\
\hline & & Human Factors & $\begin{array}{l}\text { Incomes, Unilateral industrial water-saving investments, Enterprise management } \\
\text { level, Economic efficiency of enterprises, The proportion of state-owned } \\
\text { enterprises, Research expenditure within the enterprise, the matching between } \\
\text { the industrial layout and water resources, City macroeconomic policies, Urban } \\
\text { water conservancy construction, Government-saving investments and incentives }\end{array}$ \\
\hline
\end{tabular}

\section{IMPROVED SERIES GRAY NEURAL NETWORK MODEL}

\section{A Improved conceptual model series gray neural network}

Grey system theory is based on "some of the information known, some information is unknown," the "small sample data", "information poor" and uncertain system for the study[6], for analysis, modeling, solving, predicted a transverse large, strong penetration of emerging disciplines. The difference between the use of swaps to achieve the establishment of Differential Equations and continuous dynamic differential equations by the idea of discrete data sequence[7].

BP (Back Propagation) neural network is a typical error back propagation algorithm by former training multilayer feed forward networks[8], with a self-learning, selforganizing, adaptive and fault-tolerance and other fine features. It has proved to have a hidden layer of BP algorithm three networks can approximate any nonlinear function with arbitrary precision, widely used[9] in pattern recognition, predictive analysis, nonlinear optimization, and other fields.

Improved series gray neural network model, the more traditional parallel gray neural network, using a nonlinear fitting ability of neural networks to solve the parallel gray neural network weights in question, taking into account non-linear relationship between the predicted results. In order to solve the problems of the conventional precision series gray neural network model, taking into account the effects of other factors on the predicted impact. In this paper, the improved series gray neural network model by gray prediction errors of the weights of the neural network training process and the impact of non-linear effect correction factor for industrial water demand, to achieve the best fit of the predicted and observed values together.

$B$ The calculation of improved series gray neural network

Step one: The levle ratio about the time series of industrial water demand

1.The time series of industrial water demand $X=(X(1), X(2), \cdots, X(\mathrm{n}))$

2. The smoth ratio of $X$ :

$$
\rho(k)=\frac{\mathrm{X}(k)}{\sum_{i=1}^{k-1} X(i)}, k=2,3,4, \cdots, n
$$

3. The level ratio of $X$

$$
\sigma(k)=\frac{X(k)}{X(k-1)}, k=2,3,4, \cdots, n
$$

4.The judgement

If $\rho(k)$ satisfy the following three conditions:

$$
\begin{aligned}
& \text { I. } \frac{\rho(k+1)}{\rho(k)}<1, k=2,3,4, \cdots, n-1 \\
& \text { II. } \rho(k)<\varepsilon, k=3,4, \ldots, n \\
& \text { III. } \varepsilon<0.5
\end{aligned}
$$

$\rho(k)$ is the Quasi-smooth sequence of $X$ If $\sigma(k)$ satisfy the following three conditions: 


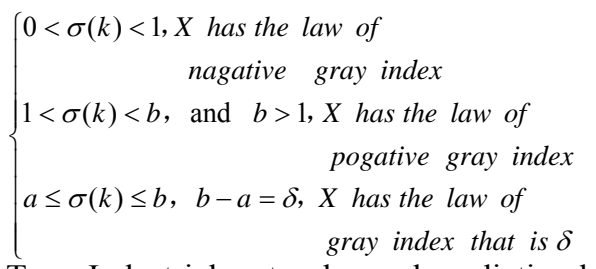

Step Two: Industrial water demand prediction based on the model of standard GM

The original data series: $X^{(0)}=\left(X^{(0)}(1), X^{(0)}(2), \cdots, X^{(0)}(\mathrm{n})\right) \quad, \quad X^{(0)}(k) \geq 0$, $k=1,2, \ldots, n$. If $X^{(0)}$ satisfy the above conditions, then we can establish the GM model[10].

1.Generate the accumulated sequence(1- AGO)

$$
\begin{gathered}
X^{(1)}=\left(X^{(1)}(1), X^{(1)}(2), \cdots, X^{(1)}(\mathrm{n})\right) \\
X^{(1)}(k)=\sum_{i=1}^{k} X^{(0)}(i), k=1,2, \ldots, n
\end{gathered}
$$

2.Determine the data matrix $\mathrm{B}, \mathrm{Y}$. Take the background value:

$$
\begin{aligned}
& Z^{(1)}(k)=0.5\left(X^{(1)}(k)+X^{(1)}(k-1)\right), k=2,3, \cdots, n \\
& \text { Then } Z^{(1)}=\left(Z^{(1)}(1), Z^{(1)}(2), \cdots, Z^{(1)}(n)\right) ;
\end{aligned}
$$

The differential equation about $\mathrm{X}^{(1)}$

$\frac{\mathrm{d} X^{(1)}}{d t}+a X^{(1)}=b ; a$ is the development of gray number, $b$ is the endogenous control of gray number.

$$
\mathrm{B}=\left[\begin{array}{cc}
-Z^{(1)}(2) & 1 \\
-Z^{(1)}(3) & 1 \\
\vdots & \vdots \\
-Z^{(1)}(n) & 1
\end{array}\right] \quad Y=\left[\begin{array}{c}
X^{(0)}(2) \\
X^{(0)}(3) \\
\vdots \\
X^{(0)}(n)
\end{array}\right]
$$

3.Least square estimation

$$
\hat{\mathrm{a}}=(a, b)^{T}=\left(B^{T} B\right)^{-1} B^{T} Y
$$

5.Generate the model of data series

$$
\hat{\mathrm{X}}^{(1)}(k+1)=\left(X^{(0)}(1)-\frac{b}{a}\right) e^{-a k}+\frac{b}{a}
$$

5.Set up the prediction model of raw data $\mathrm{X}^{(0)}$

$$
\begin{aligned}
& \hat{X}^{(0)}(1)=X^{(0)}(1), \\
& \hat{X}^{(0)}(k)=\hat{X}^{(1)}(k)-\hat{X}^{(1)}(k-1)=\left(1-e^{a}\right)\left(X^{(0)}(1)-\frac{b}{a}\right) e^{-a(k-1)} \\
& \quad(k=2,3, \cdots, n) \text {; when } k=2,3, \cdots, n, \hat{X}^{(0)}(k) \text { is the fitted }
\end{aligned}
$$

Value of $\mathrm{X}^{(0)}(k)$, when $k>n, X \quad(k)$ is the predictive value of $\mathrm{X}^{(0)}(k)$.
Step Three: Industrial water demand prediction based on the model of unbiased GM

Thers is always a certain bias by using the standard GM model, so we correct the parameters of $a$ and $b$, which is called WPGM.

1-3 are same with the standard GM.

4. Determine the parameters of WPGM

$$
\hat{\mathrm{a}}=\ln \frac{2-a}{2+a}, A=\frac{2 b}{2+a}
$$

5.Set up the prediction model of raw data

$$
\hat{X}^{(0)}(1)=X^{(0)}(1), \hat{X}^{(0)}(k)=A e^{\hat{a}(k-1)}, k=2,3, \cdots, \mathrm{n} .
$$

Step Four: Industrial water demand prediction based on the model of PGM

1,3-5 are same with the standard GM.

2.Determine the optimal weights: P,Determine the data matrix $: \mathrm{B}, \mathrm{Y}$. Take the background value:

$$
Z^{(1)}(k)=P X^{(1)}(k)+(1-P) X^{(1)}(k-1), k=2,3, \cdots, n
$$

Then $Z^{(1)}=\left(Z^{(1)}(1), Z^{(1)}(2), \cdots, Z^{(1)}(\mathrm{n})\right)$;

$P$ is start from 0.01 ,increase with 0.01 , In order to solve the average simulation opposite error

$$
\left(\bar{\Delta}=\frac{1}{n} \sum_{k=1}^{n}\left|\frac{\varepsilon^{(0)}(k)}{X^{(0)}(k)}\right|, \varepsilon^{(0)}(k)=X^{(0)}(k)-\hat{X}^{(0)}(k)\right), \text { till }
$$

$p=0.99$, the minimum value of $P$ is the optimal weights.

Step Five: Industrial water demand prediction based on the model of PGM-WPGM

Make up the model of PGM and the WPGM, the The core idea is: This portfolio model calculates the optimal weights $\mathrm{P}$, and its corresponding minimum relative error, background values, etc., and then find the predicted value.

Step Six: Comparison and selection

To compare the predicted value and the real value of the above four models, choose the smaller value of the average relative error named $\mathrm{Q}$, the larger value of the gray correlation degree named $\mathrm{R}$, the smaller value of the posterior variance ratio named $C$, the larger value of the small error probability named P. This model's predicted value as a part of the neural network input.

Step Seven: Industrial water demand key factor in the selection - gray correlation analysis

Gray relational analysis is the method that study the uncertainties correlation of system factors, make quantitative analysis on development trend of the system dynamic process, compute correlation degree of each factor, depict the gray order among the factors. By comparing the correlation to identify the main factors affecting the system development outcomes[11].

1.Determine the parameter sequence and comparative sequence

$\eta_{0}(i), i=1,2, \cdots, n$ is time series that standard output of industrial water demand, it is the parameter sequence;

$\eta_{\mathrm{k}}(i), k=1,2, \cdots, m ; i=1,2, \cdots, n$ is time series that standard input of industrial water demand, it is the comparative sequence. 
2.Obtain the correlation coefficient

Define correlation coefficient of $\mathrm{X}_{0}(i)$ and $\mathrm{X}_{\mathrm{k}}(i)$ at $\mathrm{i}=\mathrm{r}$

$$
\begin{aligned}
& \delta_{0 \mathrm{k}}(r)=\frac{\min _{k} \min _{r}\left\{\left|\eta_{0}(r)-\eta_{k}(r)\right|\right\}+\varphi \max _{k} \max _{r}\left\{\eta_{0}(r)-\eta_{k}(r) \mid\right\}}{\left\{\left|\eta_{0}(r)-\eta_{k}(r)\right|\right\}+\varphi \max _{k} \max _{r}\left\{\left|\eta_{0}(r)-\eta_{k}(r)\right|\right\}}, \\
& r=1,2, \cdots, n ;
\end{aligned}
$$

$\varphi$ is the resolution coefficient, This value shows that the greater the resolution, the smaller the coefficient,

$0<\varphi<1$, usually the value is 0.5 .

3.Calculate correlative degree

The correlative degree of comparative sequence named

$$
\xi_{\mathrm{k}}: \xi_{\mathrm{k}}=\frac{1}{n} \sum_{r=1}^{n} \delta_{0 k}(r)
$$

4.Comparison and selection

If $\xi_{\mathrm{k}}>0.6$,make it be the key factor influencing industrial water demand, and the value as a part of the neural network input.

Step Eight: The calculation of BP neural network

By use of the additional momentum method and auto adjustive learning rate, the $\mathrm{BP}($ Back Propagation) neural network is modified.

1. Input Layer: Optimal results of model's predicted value and key influencing factors.

2. Hidden Layer: Determine the number of hidden layer neurons[12],the value make the total mean square error is minimized

$$
\mathrm{s}=\sqrt{t+l}+c
$$

( $s$ :the number of hidden layer nodes; $t$ :the number of input layer nodes; $l$ :the number of output layer nodes; $c$ : constant between 1 to 10 )

3. Weight adjustment based on the additional momentum method

The method reduce the shock of learning process by adding a damping term[13].The formula of weight adjustment:

$$
\begin{aligned}
& \Delta W_{i j}(k+1)=(1-\alpha) \eta \delta_{i}+\alpha \eta \Delta W_{i j}(k) \\
& \alpha= \begin{cases}0 & \text { when } \mathrm{E}(k)>0.14 * \mathrm{E}(k-1) \\
0.95 & \text { when } \mathrm{E}(k)<\mathrm{E}(k-1) \\
\alpha & \text { the others }\end{cases}
\end{aligned}
$$

$k$ is the training times, $\alpha$ is the momentum factor, $0 \leq \alpha \leq 1$, usually the value is $0.95, \delta_{i}$ is the node error, $\eta$ is the learning rate.

\section{EMPIRICAL ANALYSIS-INDUSTRIAL WATER DEMAND PREDICTION OF NANJING}

\section{A. Water resources situation of Nanjing}

Nanjing has a subtropical monsoon climate with four distinct seasons and rainfall. According to statistics, the average annual precipitation is $1070 \mathrm{~mm}$, the average total water resources is 2.147 billion $\mathrm{m}^{3}$, the entry of water up to 916.2 billion $\mathrm{m}^{3}$.Local water resources per capita less than
$400 \mathrm{~m}^{3}$, only $1 / 6$ of the national per capita. By the end of 2013, the total urban water supply of Nanjing is 1.267 billion $\mathrm{m}^{3}$, of which, industrial water is 0.473 billion $\mathrm{m}^{3}$, accounting for $37.38 \%$ of the total water consumption, water consumption is lower than only 13 percentage points. To this end, the scientific prediction of industrial water demand plays an important role to improve the level of the water in Nanjing, the adjustment of industrial structure and optimize water resources allocation .

\section{B. Industrial water demand prediction based on the improved series gray neural network}

(1) The levle ratio about the time series of industrial water demand

$X=(X(1), X(k), \cdots, X(12))$ is the time series of total industrial water, the results are shown in Table II, $k$ represents a different time interval.

1. When $k=2,3, \cdots, 11, \rho(k+1) / \rho(k)<1$; when $k=3,4, \cdots, 12$,the smoth ratio $\rho(k) \in[0,0.4065]$,clearly $0.4065<0.5$,so the time series of industrial water demand satisfy the quasismoth conditions.

2. When $k=2,3, \cdots, 12$,the level ratio $\sigma(k) \in[0.7279,1.0883]$,clearly 1.0883$0.7279=0.3604<0.5$, so the time series of industrial water demand satisfy the accurate index rate.

TABLE II The Value of $\rho(k+1) / \rho(k)$

\begin{tabular}{|c|c|c|c|c|c|c|}
\hline$k$ & $\mathbf{2}$ & $\mathbf{3}$ & $\mathbf{4}$ & $\mathbf{5}$ & $\mathbf{6}$ & $\mathbf{7}$ \\
\hline$\rho(k)$ & $\begin{array}{c}0.85 \\
39\end{array}$ & 0.4226 & 0.2935 & 0.2172 & 0.1566 & 0.1474 \\
\hline$\rho(k+1) / \rho(k)$ & $\begin{array}{c}0.49 \\
49\end{array}$ & 0.6945 & 0.7400 & 0.7210 & 0.9413 & 0.6343 \\
\hline$\sigma(k)$ & $\begin{array}{c}0.85 \\
39\end{array}$ & 0.9175 & 0.9879 & 0.9573 & 0.8777 & 1.0883 \\
\hline$k$ & $\mathbf{8}$ & $\mathbf{9}$ & $\mathbf{1 0}$ & $\mathbf{1 1}$ & $\mathbf{1 2}$ & $\mathbf{1 3}$ \\
\hline$\rho(k)$ & $\begin{array}{c}0.09 \\
35\end{array}$ & 0.0868 & 0.0780 & 0.0708 & 0.0645 & -- \\
\hline$\rho(k+1) / \rho(k)$ & $\begin{array}{c}0.92 \\
83\end{array}$ & 0.8986 & 0.9077 & 0.9110 & -- & -- \\
\hline$\sigma(k)$ & $\begin{array}{c}0.72 \\
79\end{array}$ & 1.0146 & 0.9774 & 0.9778 & 0.9752 & -- \\
\hline
\end{tabular}

(2) Construction of improved gray neural network model

The input layer is consist of optimal results of model's predicted value and key influencing factors. And the number of hidden layer is determined by formula (17), the value make the total mean square error is minimized. The numbers of output layer are the predicted values. The initial value of $\alpha$ is 0.7 and $\eta$ is 0.1 .Network training's stop 
condition is that: the maximum number of network learning named $\mathrm{N}>5000$ or the output error named $\mathrm{E}<1 \mathrm{e}-3$.

(3) Industrial water demand forecasting based on the improved series gray neural network

Select the data of Nanjing from 2000 to 2009 as training samples of improved series gray neural network model. By use of neural network forecasting model after training, we can make the industrial water demand prediction test of Nanjing in 2010, in 2011.From the table 3,the predicted value of 2011 is 4153.7 billion $\mathrm{m}^{3}$ and the value of 2012 is 4061 billion $\mathrm{m}^{3}$. The relative errors are $1.62 \%$ and $1.87 \%$.

\section{Performance Comparison of model predictions}

In order to compare accuracy of the the improved series gray neural network model, we also use traditional neural network model to simulate the industrial water demand forecast, and the results are shown in Table III.

Compare the above three kinds of prediction results, the improved series gray neural network model to predict the result is better than the traditional neural network model and the model of PGM-WPGM, thus proving the feasibility of the model. The industrial water demand forecast values of Nanjing 2015-2016 are shown in Table IV.

TABLE IV. Industrial Water Demand Prediction of Nanjing Based on Improved Series Gray Neural Network Model

\begin{tabular}{|c|c|}
\hline Year & Predicted Value \\
\hline 2015 & 39428 \\
\hline 2016 & 38228 \\
\hline
\end{tabular}

\section{CONCLUSION}

Based on the GM, WPGM, PGM, PGM-WPGM and the traditional neural network model, we build the improved series gray neural network effectively weaken the randomness predictors, uncertain and nonlinear relationships and other related issues. Make an empirical forecast of Nanjing industrial water demand, and find that the model is good stability and adaptability which makes it better than the predictions of individual models to predict the results of the above, and the predicted results and the actual amount of water is very close. Finally, the model further predicts the Nanjing industrial water demand of 2015 - 2016.

\section{REFERENCES}

[1]China Centre for International Eurasian Academy of Sciences, China Urban Development Report(2012/2013)[R] ,Beijing: Foreign Languages Press, 2012.

[2]National Bureau of Statistics of China, China City Statistical Yearbook 2014 [M],Beijing: China Statistics Press, 2014.

[3]Y.Huang,H.F.Wang,G.P.Xing,D.X.Sun,A hybrid grey relational analysis and support vector machines approach for forecasting consumption of spare parts,in:Artificial Intelligence and Education(ICAIE),2010 International Conference on,29-30 Oct.2010.

[4]C.C.Wang,Methods and application for supply and demand prediction of urban water resources,North China Electric Power University,2013.

[5]F.W.Hu,Water demand driving factors and the forecast analysis of Zhengzhou,Zhengzhou University,2007:16-18.

[6]W.He,H.Q.Zhang,Analysis of real eatate price trend based on modified gray neural network model,Journal of WUT,2014,01:135-139.

[7]L.Ai,J.T.Cheng,J.Hua, Water quality prediction based on improved evidence theory combining with gray neural network, Yellow River,2014,03:46-48.

[8]Y.Q.Lv,Y.He,Prediction model of tertiary industry development trend based on gray neural network,Journal of Statistics and Decision Making,2011,04:157-159.

[9]J.S.Li,H.Q.Wang,G.F.Wang,Oil pipe transportation expense prediction based on the grey neural network,Pipeline Technique and Equipment,2014,04:10-11+57.

[10]Y.G.Zhang,Y.Wang,J.Sun,Y.L.Gao,Study on wind power capacity prediction based on the optimal combination of the grey neural network,Electrical Measurement \& Instrumentation,2014,22:30-34.

[11]P.W.Yuan,S.X.Song,X.Q.Dong,Study on fire accident prediction based on optimized grey neural network combination model,Journal of Safety Science and Technology,2014,03:119-124.

[12]J.Q.Zhao,Q.S.Dai,Research on prediction and assignment of Chinese freshwater resources based on gray neural network algotithm and multi-objective optimization, Water Saving Irrigation,2014,10:33-35.

[13]L.L.Li,L.Qiu,Vessel traffic accident forecasting using a combination gray neural network model,Journal of Transportation Information and Safety,2014,03:110-113+118. 
TABLE III. Comparative Results of Different Prediction Models

\begin{tabular}{|c|c|c|c|c|c|c|c|c|c|c|}
\hline \multirow[t]{2}{*}{ Year } & \multirow[t]{2}{*}{$\begin{array}{c}\text { Real } \\
\text { Value }\end{array}$} & \multicolumn{3}{|c|}{ PGM-WPGM } & \multicolumn{3}{|c|}{ Traditional Neural Network Model } & \multicolumn{3}{|c|}{$\begin{array}{c}\text { Improved Series Gray Neural } \\
\text { Network Model }\end{array}$} \\
\hline & & $\begin{array}{l}\text { Predicted } \\
\text { Value }\end{array}$ & Residual & $\begin{array}{l}\text { Relative } \\
\text { error }\end{array}$ & $\begin{array}{l}\text { Predicted } \\
\text { Value }\end{array}$ & Residual & $\begin{array}{l}\text { Relative } \\
\text { error }\end{array}$ & $\begin{array}{l}\text { Predicted } \\
\text { Value }\end{array}$ & $\begin{array}{c}\text { Residu } \\
\text { al }\end{array}$ & $\begin{array}{l}\text { Relative } \\
\text { error }\end{array}$ \\
\hline 2000 & 81821 & 81821 & 0 & 0 & 83260 & 1439 & 0.0176 & 80281 & -1540 & -0.0188 \\
\hline 2001 & 69866 & 69494 & -372 & -0.0053 & 71543 & 1677 & 0.0240 & 71010 & 1144 & 0.0151 \\
\hline 2002 & 64100 & 65360 & 1260 & 0.0197 & 63250 & -850 & -0.0133 & 64807 & 707 & 0.0110 \\
\hline 2003 & 63324 & 61473 & -1851 & -0.0292 & 64077 & 683 & 0.0108 & 64942 & 1618 & 0.0256 \\
\hline 2004 & 60623 & 57817 & -2806 & -0.0463 & 62859 & 2236 & 0.0369 & 61837 & 1214 & 0.0200 \\
\hline 2005 & 53208 & 54378 & 1170 & 0.0220 & 50878 & -2330 & -0.0438 & 51577 & -1631 & -0.0307 \\
\hline 2006 & 57908 & 51144 & -6764 & -0.1168 & 56133 & -1775 & -0.0307 & 59131 & 1223 & 0.0211 \\
\hline 2007 & 42154 & 48102 & 5948 & 0.1411 & 40220 & -1934 & -0.0459 & 40953 & -1201 & -0.0285 \\
\hline 2008 & 42771 & 45241 & 2470 & 0.0577 & 44655 & 1884 & 0.0440 & 43732 & 961 & 0.0225 \\
\hline 2009 & 41803 & 42550 & 747 & 0.0179 & 43790 & 1987 & 0.0475 & 40897 & -906 & -0.0217 \\
\hline 2010 & 40876 & 40019 & -857 & -0.0210 & 41868 & 992 & 0.0243 & 41537 & 661 & 0.0162 \\
\hline 2011 & 39864 & 37639 & -2225 & -0.0559 & 41678 & 1814 & 0.0455 & 40610 & 746 & 0.0187 \\
\hline \multicolumn{2}{|c|}{$\begin{array}{c}\text { The Average } \\
\text { Relative Error }\end{array}$} & \multicolumn{3}{|c|}{0.0444} & \multicolumn{3}{|c|}{0.0320} & \multicolumn{3}{|c|}{0.0208} \\
\hline
\end{tabular}

